\title{
A função da comunicação na autoavaliação das Instituições de Ensino Superior do ABC Paulista
}

\section{The role of communication in self-evaluation of Higher Education establishments of ABC Paulista region}

\author{
Claudemir Martins da Silva ${ }^{1}$ \\ Elias Estevão Goulart ${ }^{2}$
}

\begin{abstract}
RESUMO
O artigo discorre sobre o papel que a comunicação apresenta no compartilhamento e na socialização dos resultados apurados no processo de autoavaliação junto à comunidade acadêmica de Instituições de Ensino Superior. O estudo fundamenta-se em referenciais bibliográficos que tratam da avaliação institucional e pesquisa de campo exploratória desenvolvida em quatro instituições de ensino superior localizadas na região do $\mathrm{ABC}$ Paulista.

Palavras-chave: avaliação institucional; comissão própria de autoavaliação; comunicação organizacional; novas tecnologias da informação e comunicação.
\end{abstract}

\begin{abstract}
The article discusses the role that the communication presents in sharing and socialization of the results obtained in the process of self-evaluation along the academic community of higher education institutions. The study is based on bibliographic references which deals with the institutional evaluation and
\end{abstract}

${ }^{1}$ Mestre em Comunicação pela Universidade Municipal de São Caetano do Sul, Brasil. E-mail: claudemir_uniabc@yahoo.com.br

${ }^{2}$ Doutor em Engenharia pela Escola Politécnica da Universidade de São Paulo (POLI/USP), Professor do Programa de Mestrado em Comunicação da Universidade Municipal de São Caetano do Sul, Brasil. E-mail: profelias_fsa@yahoo.com.br 
exploratory field research developed in four higher education institutions located in the region of $\mathrm{ABC}$ Paulista.

Keywords: institutional assessment; commission's own self-evaluation; organizational communication; new information and communication technologies.

\section{Introdução}

As avaliações nas Instituições de Ensino Superior (IES) sempre estiveram presentes no ensino superior, seja em sala de aula ou institucionalmente, porém, nessa década ganharam profundidade nas IES, face sua obrigatoriedade e utilização como ferramenta imprescindível na reorientação das estratégias das universidades e condução de melhorias nos aspectos de ensino, pesquisa e gestão (DIAS SOBRINHO; RISTOFF, 2000).

Em 14 de abril do ano de 2004, o Estado, buscando integrar os sistemas avaliativos, instituiu o Sistema Nacional de Avaliação do Ensino Superior (SINAES) por meio da Lei 10.861, com o propósito de avaliar o ensino superior e congregar os sistemas avaliativos praticados pelos demais órgãos que regulamentam as atividades das IES no Brasil.

O SINAES apresenta uma ampla visão de avaliação institucional, ao considerar o processo educativo, a missão institucional e, sobretudo, oferecer orientação detalhada sobre a aplicabilidade e a execução que extrapolam a condição de medição de aspectos performáticos das IES (CONAES, 2004; BRASIL, 2009).

Dias Sobrinho e Ristoff, ao abordar o conceito de avaliação, chamam-nos a atenção sobre a multiplicidade de significados da avaliação e sua superação de abordagens tecnicistas, conforme as palavras dos autores: "[...] Ela produz sentidos, consolida valores, afirma interesses, provoca mudanças, transforma. [...]" (2000, p. 37).

Para se construir um processo de autoavaliação institucional nos moldes sugeridos pelo SINAES, devem ser considerados aspectos importantes, como: ética, métodos, técnicas, infraestrutura, cultura organizacional, dentre outros (DIAS SOBRINHO, 2000).

Para atender as finalidades desse artigo, elencaram-se, a partir da literatura que trata da avaliação institucional e pressupostos versados no SINAES, cinco aspectos essenciais que as IES devem observar na operacionalização da avaliação: a) divulgação, b) envolvimento dos dirigentes, c) identificação das dificuldades, d) formas de acesso e e) construção dos relatórios. 


\section{Divulgação}

O processo de divulgação é um elemento-chave para a concretização da avaliação institucional interna, pois é o momento em que a comunidade acadêmica passa a apropriar-se da avaliação institucional como instrumento de vazão aos seus anseios ou de consulta na tomada de decisão, no caso de gestores (SANCHES, 2009).

Os recursos comunicativos variam de uma IES para outra, mas via de regra são eles: intranet, sítio institucional, extranet, informativos, jornal, murais, faixas e banners, novas tecnologias da informação e da comunicação (TICs) (RECUERO, 2009).

Além dos recursos mencionados, as comissões responsáveis pela avaliação também realizam reuniões segmentadas e coletivas com alunos, professores, coordenadores, colaboradores e comunidade externa, a fim de discutir estratégias de aplicação, divulgação dos resultados e metodologias da pesquisa para aprimorar o processo avaliativo e obter a devolutiva, tanto de avaliadores como de avaliados. Alguns autores chamam esse momento de meta-avaliação, ou seja, a avaliação da avaliação (SANCHES, 2009).

Nesse cenário, a ideia de divulgação traz em seu bojo o aspecto da imparcialidade, pois a mensagem será revestida de intencionalidades persuasivas e com vistas a convencer o outro sobre sua relevância. Tanto os autores referenciados no estudo como os órgãos reguladores, como o CONAES, SINAES, MEC e INEP, nominam esse processo de sensibilização.

Isto posto, entende-se que a comunicação formal e informal pode desempenhar papel crucial na avaliação institucional, porque é por intermédio dela que a comunidade acadêmica passar a conhecer a avaliação, seus resultados e suas finalidades (BUENO, 2009).

\section{Envolvimento dos dirigentes}

Para Belloni (2000), a construção coletiva e democrática da avaliação deve contar com o envolvimento da gestão superior da IES (reitores, diretores, membros com poder de decisão), desde a proposta inicial, passando pela execução até a divulgação dos resultados, para legitimar a comissão e todas as etapas do processo avaliativo. 
A avaliação, que visa a mudanças e transformações nas práticas administrativas e acadêmicas, precisa contar com vontade política por parte do grupo dirigente da instituição, pois constitui-se condição básica para o necessário aprimoramento do planejamento e da gestão da instituição, uma vez que propicia a constante reorientação de suas ações, como assinala Sanches (2009).

A legitimação do grupo dirigente valida as ações previstas no planejamento das comissões de avaliações e seu envolvimento, mesmo que de forma indireta, sinaliza para a comunidade acadêmica a seriedade e a importância da avaliação institucional na busca da melhoria da instituição, conforme especificado no documento do MEC/CONAES (2004), que trata dos requisitos para implantação da autoavaliação institucional.

\section{Identificação das dificuldades}

A avaliação institucional tem sido executada em muitas instituições de ensino superior distribuídas pelo país, face sua obrigatoriedade, mas ainda encontra diversas dificuldades por razões políticas, ideológicas ou até mesmo econômicas. Não se discute mais se a avaliação deve ou não ser efetuada, mas como deve se processar e como romper as resistências que ela desencadeia (GADOTTI, 2009).

A avaliação institucional não pode ser vista como um instrumento de controle burocrático e centralização, em conflito com a autonomia, mas deve ser institucionalizada como um processo necessário de melhoria da instituição nos aspectos de ensino, pesquisa, extensão e de processos internos. Ela deve ser mais instituída até tornar-se uma necessidade explícita nas instituições de ensino (GADOTTI, 2009).

A identificação das dificuldades tornou-se condição sine qua non para a operacionalização da avaliação institucional, pois será a partir desses "gargalos" que as comissões poderão amenizar as resistências em relação ao processo avaliativo (SORDI; LUDKE, 2009).

Segundo Sordi e Ludke (2009), a questão da resistência dos públicos em relação à avaliação institucional sugere que o processo de sensibilização deve começar na formação do docente, ou seja, quando este estabelece o primeiro contato com a instituição. 


\section{Formas de acesso}

Dias Sobrinho e Ristoff (2000) sugerem que as instituições devem disponibilizar previamente os documentos e relatórios produzidos na avaliação institucional para sua comunidade acadêmica, com vistas a estimular a discussão internamente e, posteriormente, transcender os "muros" da instituição.

Para propiciar esse momento, as instituições ou comissões recorrem a sua comunicação organizacional, tradicional ou não, buscando fornecer esses elementos e estimular as discussões necessárias ao processo, pois a avaliação só se justifica se a comunidade acadêmica participar efetivamente de todas as etapas do processo (KUNSCH, 1992).

Cabe às comissões se debruçar sobre a comunicação organizacional das instituições, para verificar suas possibilidades, entender seus fluxos comunicativos, conforme assinala Kunsch (2003), e utilizá-los de acordo com a estrutura e a cultura da organização, para que todos os públicos da comunidade acadêmica tenham acesso às informações e possam manifestar suas percepções sobre o processo avaliativo.

\section{Uso das Tecnologias da Informação e da Comunicação (TICs)}

Com a ampliação das possibilidades comunicativas das TICs, as IES buscaram investir em infraestrutura tecnológica, criando mecanismos comunicativos (internos e externos) integrados, com o propósito de expandir sua abrangência e audiência.

Dentre esses recursos, destaca-se a intranet, que interliga os computadores de uma organização, permitindo a troca e o compartilhamento de informações em rede privativa. Nos últimos anos a intranet, ganhou importância exponencial nas organizações devido a sua capacidade de permitir a troca de informações de modo rápido e seguro no ambiente organizacional (JOHANSSON, 2010).

Atualmente, as tecnologias da informação e da comunicação (TICs) passaram de transmissoras de informação para ditadoras de comportamentos das organizações. Sendo assim, sustenta-se que esse advento tecnológico tem sido fator decisório para o desenvolvimento da comunicação organizacional e, consequentemente, das organizações. Nas palavras de Kunsch (1992, p. 110), "as inovações tecnológicas têm de ser incessantemente incorporadas pelas instituições". 
Li (2009), no artigo intitulado "A research perspective: online and traditional evaluation of teaching in the higher education settings", nos chama a atenção para os ambientes onde essas novas tecnologias ganham cada vez mais espaço e adeptos.

Castells (1999) define esse fenômeno como sociedade informacional ou sociedade em rede, cuja estrutura básica é apresentada em redes, divisão típica da nova sociedade que vem sendo difundida sobre o planeta, reivindicando uma universalidade sem paralelo, além de decretar o fim da geografia como a conhecemos.

Com o surgimento da $\mathrm{Web} 2.0$, que pode ser entendida como a convergência dos meios de comunicação via computador, baseada na tecnologia da hipermídia, cujas principais características são conteúdo, colaboração, compartilhamento, interatividade e interconectividade, e as diversas possibilidades de acesso dos indivíduos ao ciberespaço, a permissão de acesso a todos e ao mesmo tempo potencializou os modos de interação social (RECUERO, 2005).

\section{Metodologia da pesquisa}

Foi realizada pesquisa de campo exploratória qualitativa, com os responsáveis pelas comissões de avaliação e pesquisa documental para o levantamento de dados e informações e subsidiar a análise e a discussão dos resultados. As IES que participaram do estudo serão referenciadas pelas letras A, B, C e D, visando à preservação do anonimato dos participantes.

A técnica utilizada foi a entrevista fechada em que, nas palavras de Duarte e Barros (2005, p. 63), "permite identificar as diferentes maneiras de perceber e descrever os fenômenos". Teve como instrumento um questionário, contendo dez questões abertas relacionadas à temática do estudo.

Os dados foram coletados no ano de 2010, entre os meses de abril, maio e junho. Após a identificação das instituições, foi estabelecido contato inicial, via telefone e e-mail, com os respectivos responsáveis pela Comissão Própria de Avaliação (CPA) de quatro IES localizadas na região do ABC Paulista, que compreende os municípios de São Caetano do Sul, Santo André, Mauá, São Bernardo do Campo, Diadema, Ribeirão Pires e Rio Grande da Serra, e encaminhado previamente o roteiro da entrevista.

As entrevistas e documentos foram explorados sob diferentes ângulos, tendo em vista a construção de um quadro conceitual elaborado a partir da transcrição das entrevistas gravadas e dos subsídios trazidos da literatura 
específica e que tratam das áreas de conhecimentos macros em que o estudo estabelece relações.

\section{Resultados apurados}

\section{Formas de divulgação}

Para identificar as formas de divulgação utilizadas pelas IES, analisamos os relatórios das IES e, no decorrer das entrevistas com os responsáveis, perguntamos se as comissões definiam antecipadamente as estratégias comunicativas para estimular a participação da comunidade acadêmica na avaliação institucional, vislumbrando identificar quais canais são mais eficazes, se há ou houve implementação das ações comunicativas no decorrer da avaliação, e assim por diante.

Nesse sentido, as Tabelas 1 e 2 apresentam os resultados das ações comunicativas empregadas pelas comissões e os percentuais de adesão à avaliação nas IES. Destaca-se que os dados foram extraídos dos relatórios disponibilizados pelas IES das respostas cedidas pelos entrevistados, no ato da entrevista.

Tabela 1 - Estratégias de divulgação da avaliação adotadas pelas IES pesquisadas

\begin{tabular}{|c|c|c|c|c|c|c|c|c|c|}
\hline \multicolumn{5}{|c|}{ Comunicação Tradicional } & \multicolumn{5}{|c|}{ Comunicação por TICs } \\
\hline \multirow{2}{*}{ Modalidade } & \multicolumn{4}{|c|}{ Instituição } & \multirow[t]{2}{*}{ Modalidade } & \multicolumn{4}{|c|}{ Instituição } \\
\hline & $\mathbf{A}$ & B & $\mathbf{C}$ & D & & $\mathbf{A}$ & B & $\mathbf{C}$ & D \\
\hline Banners & SIM & SIM & NÃO & SIM & Blog & SIM & $\mathrm{NÃO}$ & NÃO & $\mathrm{NÃO}$ \\
\hline Cartazes & SIM & SIM & $\mathrm{NÃO}$ & SIM & E-mail & SIM & SIM & NÃO & SIM \\
\hline Folders & SIM & SIM & $\mathrm{NÃO}$ & SIM & Extranet & SIM & SIM & $\mathrm{NÃO}$ & SIM \\
\hline Informes & SIM & SIM & $\mathrm{NÃO}$ & SIM & Fóruns & SIM & $\mathrm{NÃO}$ & $\mathrm{NÃO}$ & $\mathrm{NÃO}$ \\
\hline Jornais & SIM & NÃO & NÃO & SIM & Informes & SIM & SIM & NÃO & SIM \\
\hline Periódicos & SIM & NÃO & NÃO & NÃO & Internet & SIM & SIM & NÃO & SIM \\
\hline Murais & SIM & SIM & NÃO & SIM & Intranet & SIM & SIM & NÃO & NÃO \\
\hline Faixas & SIM & $\mathrm{NÃO}$ & NÃO & SIM & Móbile & NÃO & NÃO & NÃO & NÃO \\
\hline Rádio & NÃO & SIM & NÃO & NÃO & Orkut & SIM & NÃO & NÃO & NÃO \\
\hline Reuniões & SIM & SIM & SIM & SIM & Twitter & SIM & SIM & NÃO & NÃO \\
\hline TV & NÃO & SIM & NÃO & NÃO & Outros & SIM & SIM & NÃO & NÃO \\
\hline
\end{tabular}

FONTE: relatórios de avaliação das IES disponíveis nos sítios referentes aos anos 2009 e 2010. 
Tabela 2 - Percentual de respondentes por IES

\begin{tabular}{|l|c|c|c|c|c|c|c|c|}
\hline IES & Alunos & Professores & $\begin{array}{c}\text { Funcio- } \\
\text { nários }\end{array}$ & $\begin{array}{c}\text { Coorde- } \\
\text { nadores }\end{array}$ & Egressos & $\begin{array}{c}\text { Pós- } \\
\text { graduação }\end{array}$ & $\begin{array}{c}\text { Empresas } \\
\text { parceiras }\end{array}$ & Total \\
\hline A & $83 \%$ & $93 \%$ & $52 \%$ & $85 \%$ & $20 \%^{*}$ & $23 \%$ & $12 \%^{*}$ & $73 \%$ \\
\hline B & $25 \%$ & $69 \% * *$ & $51 \%$ & $60 \%$ & $\begin{array}{c}\text { não } \\
\text { consta }\end{array}$ & $14,2 \%$ & não consta & $27 \%$ \\
\hline C & $23 \%$ & $51,3 \%$ & $67 \%$ & $77,7 \%$ & $\begin{array}{c}\text { não } \\
\text { consta }\end{array}$ & não consta & não consta & $25,5 \%$ \\
\hline $\mathbf{D}^{* * * *}$ & $\begin{array}{c}\text { não } \\
\text { consta }\end{array}$ & não consta & $\begin{array}{c}\text { não } \\
\text { consta }\end{array}$ & $\begin{array}{c}\text { não } \\
\text { consta }\end{array}$ & $\begin{array}{c}\text { não } \\
\text { consta }\end{array}$ & não consta & não consta & $\begin{array}{c}\text { não } \\
\text { consta }\end{array}$ \\
\hline
\end{tabular}

FONTE: relatórios de avaliação das IES disponíveis nos sítios referentes aos anos 2009 e 2010.

* O percentual está representado de acordo com o universo estabelecido pela IES.

** Devido às várias modalidades de docentes, optou-se para fins didáticos em representá-los aproximadamente.

*** Os relatórios que a IES D disponibiliza são constituídos de gráficos comparativos das questões dos instrumentos, não havendo nenhuma informação sobre o número de respondentes.

Analisando-se a Tabela 2, verifica-se que as IES A e B fazem amplo uso de diversos recursos comunicativos para promover a avaliação institucional.

A análise do relatório da IES B permitiu identificar quais recursos comunicacionais são utilizados na avaliação, bem como sua operacionalização no processo. Nota-se por meio desta análise que a comunicação interpessoal (reuniões e assembleias) é utilizada de forma recorrente, em quase todos os momentos, e, para a comissão obter as devolutivas, promovem acompanhamentos e diversas ações de sensibilização da comunidade acadêmica.

A IES C desconsidera completamente os recursos comunicativos no processo avaliativo, limitando-se apenas a fazer reuniões gerais com a comunidade acadêmica. Quando arguido sobre a eficácia dos canais comunicativos, o entrevistado foi categórico em responder que não há estratégias definidas na IES.

A IES D utiliza significativamente os recursos comunicacionais tradicionais, demonstrando ter ciência da importância desses mecanismos para o processo avaliativo. Segundo relato do entrevistado, a comissão ainda não atingiu um formato ideal e as estratégias, basicamente, limitam-se às reuniões com os representantes da comunidade acadêmica. Porém, tem buscado se aprimorar a cada ciclo avaliativo.

Com relação à Tabela 2, destaca-se que a única instituição que apresenta publicamente em seu relatório todos os percentuais de participação da comunidade acadêmica na avaliação institucional é a IES A, assumindo também em seu relatório a importância da comunicação no processo avaliativo. 
As IES B e C apresentam parcialmente os percentuais e os dados apresentados pela IES D são comparativos, impossibilitando qualquer análise dos pesquisadores, mas, segundo o entrevistado, são utilizadas várias estratégias.

Ao relacionarmos as Tabelas 1 e 2, pode-se verificar, quantitativamente, que a IES A apresenta índices de participação superiores na maioria dos segmentos da comunidade acadêmica em se tratando de adesão na participação na avaliação institucional, sendo também a única instituição que demonstra e comprova em seu relatório os canais comunicativos que foram utilizados na promoção da avaliação institucional, bem como as sinergias institucionais.

Por outro lado, as outras IES não apresentam ou apenas descrevem as ações, não apresentando nenhuma evidência concreta da ação comunicativa nos relatórios, como é o caso da IES B.

A análise dos relatórios e sítio na internet deixou claro que todas as IES utilizam alguma modalidade de comunicação para promover e divulgar a avaliação institucional, mas tudo indica que as IES e suas comissões subestimam ou desconhecem a potencialidade dos canais comunicativos.

O estudo também permitiu identificar que a prática de reuniões é a única modalidade comunicativa utilizada por todas as IES, mesmo tendo disponíveis outros recursos comunicativos. Os entrevistados que já realizaram a avaliação institucional foram unânimes, em afirmar que essa modalidade comunicativa é a mais eficiente para o processo de legitimação da avaliação.

\section{Envolvimento dos dirigentes}

A partir das colocações dos entrevistados, buscou-se identificar se há ou houve o envolvimento dos dirigentes, considerando que a legislação do SINAES (2009) sugere o envolvimento efetivo dos dirigentes no processo avaliativo para legitimar a avaliação institucional e garantir sua continuidade.

Nesse sentido, entende-se que o envolvimento dos dirigentes no processo avaliativo é condição essencial para a incorporação da avaliação à dinâmica da IES, como observam Cavalieri, Macedo-Soares e Thiollent (2004, p. 80): "Os dirigentes devem interpretar as mudanças, para que as universidades não permaneçam presas aos modos tradicionais".

Destarte, esse envolvimento trata-se, portanto, da apropriação e do reconhecimento da comissão e da avaliação como instrumento de melhoria, de modo que todos os envolvidos, inclusive a alta direção, serão passíveis de mensuração, redefinindo suas próprias representações e seus valores institucionais (ROUCHY; DESROCHE, 2005). 
Com essa perspectiva, arguiram-se os entrevistados sobre a construção da avaliação institucional para verificarmos se houve ou não o envolvimento dos dirigentes na avaliação institucional.

Com a análise dos relatos e documentos, evidencia-se que os dirigentes sempre estiveram envolvidos diretamente na avaliação institucional, mesmo antes da publicação do SINAES em abril de 2004, pois em todas IES há registros de avaliação institucional. Porém, os critérios eram definidos segundo o entendimento que cada uma tinha do processo.

Os entrevistados também reconhecem que, a partir da promulgação da Lei 10.861/04 do SINAES, os dirigentes envolveram-se mais incisivamente na avaliação institucional, nomeando ou constituindo as comissões para adequar-se às novas diretrizes dos órgãos reguladores, mesmo quando essas não representavam uma precondição.

A exceção fica com a instituição $C$, em que o processo é inteiramente executado pelos dirigentes e pela instituição, mas, segundo o entrevistado, essa centralidade ocorreu após a mudança no quadro de dirigentes.

Outro aspecto importante observado nas respostas e relatórios, especificamente sobre essa questão, foi que, apesar de possuírem algum tipo de avaliação institucional implantada, todas as IES tiveram que adequar o processo, os instrumentos e a metodologia para atender às diretrizes do SINAES e as instituições A, B e D demonstram em seus relatórios essa evolução, sugerindo a não interrupção, caracterizando a busca incessante pelas IES na criação da cultura avaliativa preconizada pelo SINAES (2009) quanto à sua continuidade. Já com relação à IES C, a continuidade fica evidenciada apenas na fala do responsável, não dispondo de nenhum indício concreto em relatório ou sítio institucional.

\section{Dificuldades enfrentadas}

A avaliação institucional é um momento de tensão, em que diversos interesses são colocados à prova sob a ótica do outro e as comissões, por sua vez, desempenham o papel de mediador entre os anseios e as frustrações da comunidade acadêmica (DEMO, 2005; PIRES, 2002; DIAS SOBRINHO, 2002).

Para superar essas tensões, exige-se das comissões a postura de negociador, pois, em um processo avaliativo, as técnicas, os métodos e os instrumentos devem ser, obrigatoriamente, submetidos à validação da comunidade acadêmica (BRASIL, 2009). 
Esse é o momento crítico das comissões e, por mais que se esforcem, não conseguirão convencer a todos, pois os interesses e percepções são diversos e às vezes antagônicos (ROUCHY; DESROCHE, 2005).

Segundo o entrevistado da IES A, havia resistência dos professores e coordenadores com relação à adesão na avaliação institucional e essa resistência foi minimizada com a divulgação dos resultados para a comunidade acadêmica. Quando adotaram essa postura, esses públicos começaram a se interessar mais sobre os trabalhos realizados pela comissão e até mesmo a utilizá-los.

Já a IES B descreve em seu relatório final que um dos maiores impeditivos no processo avaliativo foi a automatização da avaliação institucional em papel, porém, segundo o relatório e a entrevistada, a instituição está desenvolvendo a ferramenta para realizar a avaliação on-line, com previsão de funcionamento para o próximo ciclo avaliativo.

Nota-se, pela análise dos relatórios e dados disponíveis no sítio da IES B, que, visivelmente, utiliza com intensidade diversos recursos da comunicação organizacional para se fazer presente, buscando a legitimidade da comunidade acadêmica por meio de sua ampla divulgação.

Por outro lado, o responsável pela avaliação institucional da IES C relata que, devido à baixa adesão da comunidade acadêmica na avaliação institucional on-line, o dirigente optou por abolir o sistema virtual e voltou a realizá-la em papel sem a prévia sensibilização da comunidade acadêmica.

Com relação à IES D, o entrevistado relata que a maior dificuldade enfrentada na última avaliação institucional foi a falta de leitura dos alunos e, apesar de publicar semestralmente, por meio impresso, os resultados da avaliação institucional, a comunidade acadêmica continua desconhecendo a comissão, mas identificam as melhorias realizadas na IES resultantes da avaliação. Relata também a dificuldade da comunidade acadêmica em fazer a distinção das siglas que predominam no meio acadêmico (PDI, PPI, PPC, CPA, entre outras) e, para minimizar esse problema, a comissão tenta participar de todas as reuniões na instituição para reforçar o papel da comissão de avaliação institucional e a importância da sua continuidade.

Todos os entrevistados reconhecem que houve ou há dificuldades a serem superadas para a realização da avaliação institucional, porém alguns segmentos listam em quase todas as IES os professores e coordenadores. Para "combater" a resistência desses grupos, as estratégias relatadas são diversas e às vezes radicais, como é o caso da IES C, onde os alunos, professores e a própria comissão são "pegos" de surpresa. 


\section{Formas de acesso}

Para dissertar sobre essa categoria, realizaram-se visitas on-line aos sítios das instituições, para verificar como e quais informações as IES disponibilizam, publicamente, sobre a avaliação institucional, bem como os relatórios finais disponibilizados publicamente pelas IES, conforme orientações do SINAES e CONAES.

Com os resultados apurados, verificou-se que, com exceção da IES C, todas as IES possuem espaços destinados em seus sítios para a promoção e a divulgação da avaliação institucional e as IES A, B e D disponibilizam os relatórios finais para consultas públicas.

Já a IES D disponibiliza os relatórios, porém a maioria são relatórios comparativos com as avaliações anteriores e as informações dispostas limitam-se a gráficos e tabelas, não se alinhando às dimensões propostas pelo SINAES.

A IES D atende a quase todos os critérios, pois em seus relatórios não constam as estratégias de divulgação ou sensibilização e a IES C não atende a nenhum critério estabelecido para a análise dos relatórios.

Não obstante, arguiram-se os entrevistados sobre como a comunidade acadêmica acessa os relatórios parciais e finais da avaliação, com o propósito de legitimar o levantamento empírico e verificar também quais canais comunicativos são mais utilizados; quais formatos; se utilizam recursos tecnológicos; se os relatórios são segmentados ou genéricos.

De acordo com as respostas obtidas, todas as IES permitem o acesso, direto ou indireto, aos resultados da avaliação institucional, porém a forma como cada uma o faz deixa evidente o baixo entendimento que as comissões das IES C e D têm da importância da comunicação organizacional e das TICs para o processo avaliativo.

Nas IES A e B, segundo os entrevistados, além do encaminhamento segmentado para as áreas e responsáveis, a comunidade acadêmica tem acesso aos demais relatórios via intranet e extranet, como descrevem em seus relatórios disponíveis nos sítios, caracterizando que essas instituições fazem uso da comunicação organizacional e de recursos tecnológicos para divulgar a avaliação institucional.

A IES C limita-se a divulgar os resultados da avaliação institucional em reuniões gerais, cuja temática da avaliação é apenas mais um item da pauta, ou seja, a comunidade acadêmica não tem acesso aos resultados e relatórios, apenas os professores e coordenadores que recebem a devolutiva da avaliação.

Na IES D, a comunidade acadêmica tem acesso aos relatórios gerais e específicos, por meio de reuniões gerais e específicas. Ressalta-se que, segundo 
o entrevistado, a IES está investindo em infraestrutura tecnológica e a comissão intenciona ampliar as possibilidades de acesso aos relatórios produzidos na avaliação institucional.

Os resultados apurados nessa categoria permitem inferir que quase todas as IES, com exceção da IES A, ainda não conseguem permitir o acesso da comunidade acadêmica satisfatoriamente e as razões são diversas, ora pela idealização exacerbada de alguns segmentos da comunidade acadêmica, ora pela incompreensão da função formativa da avaliação institucional ou simplesmente por estar em processo de consolidação.

\section{Uso das TICs}

O levantamento demonstra que as IES participantes do estudo utilizam algumas modalidades de TICs para promover avaliação institucional, sinalizando para a tendência de um novo modelo dos processos avaliativos, onde a interação assume uma grande importância na avaliação.

Verifica-se que as comissões das IES A e B assumiram as TICs como instrumento indissociável para promover a avaliação institucional e, segundo seus relatórios, em consonância com a comunicação organizacional, porém os resultados apresentados pelas duas instituições, em relação à adesão da comunidade acadêmica, são muito díspares (ver Tabela 2), pois a IES A supera a IES B em relação à adesão na avaliação institucional em todos os segmentos da comunidade acadêmica.

A comissão da IES C não utiliza nenhuma modalidade de TICs após a centralização do processo na alta direção da instituição. Porém, segundo o entrevistado a comissão já realizou algumas experiências.

Com base nos dados obtidos sobre a IES D e relacionando-os com as respostas obtidas na entrevista com o responsável pela avaliação institucional, percebe-se a predisposição da IES em relação às TICs.

Para aprofundar nas discussões e evidenciar a utilidade das TICs e ambientes colaborativos em avaliação institucional, perguntou-se aos responsáveis como realizavam a avaliação com os egressos/comunidade e se faziam uso de chats, blogs, redes sociais, SMS, ou qualquer outro recurso comunicativo que colaborasse com a disseminação da avaliação e seus resultados para os atores que não participam do cotidiano da instituição.

Os relatos sugerem que apenas a IES C desconhece ou desconsidera as possibilidades dos ambientes colaborativos e TICs para agregar à avaliação 
institucional. Segundo o estudo, a IES A é a única instituição que recorre, como relata o entrevistado, às redes sociais.

Não obstante, a partir das respostas obtidas, verificou-se se era possível acessar por meio da internet conteúdos disponibilizados nos ambientes colaborativos e nas TICs indicados nos relatórios das IES e relatados pelos entrevistados.

O resultado do levantamento demonstra que as IES participantes do estudo utilizam algumas modalidades de TICs que permitem o acesso aberto e irrestrito à comunidade em geral, sinalizando para a tendência de um novo modelo dos processos avaliativos, onde a interação assume uma grande importância na avaliação.

Verifica-se também que as IES A e B assumiram as TICs como instrumento indissociável para promover a avaliação institucional e, segundo seus relatórios, em consonância com a comunicação organizacional.

Outro aspecto que intrigou no levantamento é o montante de estratégias comunicativas realizadas pela IES B e relatadas em seu relatório final, como: Reuniões (gerais e específicas), Assembleias, Produção de DVD, Breeze (solução corporativa que permite a publicação de conteúdo de alto impacto, com rapidez e simplicidade, integrando som, imagem e os recursos gráficos do MS PowerPoint.), Boletins, Folders, Folhetos, Artigos em jornais internos e da região, Internet e Intranet, Rádio e Televisão, Fórum de Coordenadores, Assembleia de Professores, Palestras, Reuniões-Seminário, Murais, Boletins Informativos, entre outras.

Ainda assim, segundo o relatório da IES, a adesão da comunidade acadêmica à avaliação institucional não atinge participação expressiva. Portanto, o aparente uso indiscriminado da comunicação ou seu excesso pode banalizar o uso das TICs e de outros recursos da comunicação organizacional.

Com relação à IES D, relacionamos as respostas obtidas na entrevista com o responsável pela avaliação institucional e verificamos os documentos disponíveis nos ambientes colaborativos e percebe-se a predisposição da IES em relação às TICs, mas ainda não as usa a contento, pois carece de muitas informações.

\section{Considerações finais}

O desafio de alinhar as áreas da avaliação institucional, comunicação organizacional e novas tecnologias não é uma tarefa fácil e, como já foi dito na discussão dos resultados, demanda entendimentos teóricos e práticos dos recursos comunicativos, bem como o impacto que tem sobre a comunidade 
acadêmica, e as comissões de avaliação devem conhecer em profundidade os canais, as motivações e os hábitos comunicativos de sua comunidade acadêmica para ser assertiva no envio da mensagem.

Com os resultados obtidos, as análises e as discussões, observou-se que, quando a avaliação é atrelada às modalidades de comunicação organizacional e às TICs, ela representa um importante canal comunicativo para as IES face às diversas possibilidades que essas ferramentas e aplicativos dispõem para compartilhar informações.

Nesse sentido, o domínio sobre o impacto da comunicação, e especialmente das novas "mídias" que objetivam publicizar a avaliação institucional aos seus diferentes públicos, não é mais uma necessidade, mas uma obrigação do responsável pela condução do processo avaliativo. Quanto mais a comissão conhecer os métodos, as técnicas de compartilhamento de informações com sua comunidade acadêmica, mais assertiva será sua estratégia comunicativa.

Sendo assim, o estudo permite afirmar que o ato comunicativo na avaliação institucional pode contribuir para minimizar as resistências de determinados segmentos da comunidade acadêmica e agregar valor à própria instituição avaliada, cabendo às comissões o papel de criar esses mecanismos, alimentando-os com as informações de interesse de sua comunidade acadêmica.

\section{REFERÊNCIAS}

BELLONI, Isaura. Avaliação de políticas públicas. In: BELLONI, I; MAGALHÃES, H.; SOUZA, L. C. Metodologia da avaliação. São Paulo: Cortez, 2000.

BRASIL, Comissão Especial de Avaliação (CEA). Sistema Nacional de Avaliação da Educação Superior: Bases para uma nova proposta de avaliação da educação superior. 2003. Disponível em: <http://portal.mec.gov.br/arquivos/pdf/sinaes.pdf $>$. Acesso em: 20/08/2009.

. MEC/INEP. Lei $n^{\circ}$. 10.861, de 14/04/2004, DOU n. 72, de 15/4/2004, Seção 1, p. 3-4. Disponível em: <http://www.planalto.gov.br/ccivil_03/_ato2004-2006/2004/Lei/ L10.861.html >. Acesso em: 20/03/2009.

BUENO, Wilson da C. Comunicação empresarial: políticas e estratégias. São Paulo: Saraiva 2009.

CAVALIERI, Adriane; MACEDO-SOARES, T. Diana L. V. A.; THIOLLENT, Michel. Avaliando o desempenho da universidade. São Paulo: Loyola, 2004. 
CASTELLS, Manuel. Sociedade em rede. A era da informação: economia, sociedade e cultura. São Paulo: Paz e Terra, 1999.

CONAES. Diretrizes para a avaliação das instituições de educação superior. 2004. Disponível em: <http://www.portal.mec.gov.br/arquivos/>. Acesso em: 20/05/2010.

DEMO, Pedro. Universidade, aprendizagem e avaliação: horizontes reconstrutivos. Porto Alegre: Mediação, 2005.

DIAS SOBRINHO, José. Avaliação da educação superior. Petropólis: Vozes, 2000. . Avaliação democrática: para uma universidade cidadã. Florianópolis: Insular, 2002.

; BALZAN, Newton Cesar (Orgs.). Avaliação institucional: teoria e experiências. 4. ed. São Paulo: Cortez, 2008.

; RISTOFF, Dilvo. (Orgs.). Universidade desconstruida: avaliação institucional e resistência. Florianópolis: Insular, 2000.

DUARTE. Jorge; BARROS, Antônio (Orgs.). Métodos e técnicas de pesquisa em comunicação. São Paulo. Atlas, 2005.

GADOTTI, Moacir. Avaliação institucional: necessidade e condições para a sua realização. São Paulo, 2009. Disponível em: <http://www.paulofreire.org/pub/Institu/SubInstitucional1203023491It003Ps002/Avali_Institucional.pdf>. Acesso em: 10/10/2010.

JOHANSSON, C. E. Research on organizational communication: the case of Sweden. In: Annual Meeting of the International Communication Association, Dresden International Congress Centre, Dresden, 2010. Proceedings. Germany. Disponível em: <http://www. allacademic.com/meta/p92452_index.html>. Acesso em: 10/08/2010.

KUNSCH, Margarida Maria Krohling. Universidade e comunicação na edificação da sociedade. São Paulo: Loyola, 1992.

. Planejamento de relações públicas na comunicação integrada. São Paulo: Summus, 2003.

LÉVY, Pierre. Cibercultura. São Paulo: Ed. 34, 1999.

LI, Nan. A research perspective: online and traditional evaluation of teaching in the higher education settings. In: SIEMENS, G.; FULGORD, C. (Eds.). In: World Conference on Educational Multimedia, Hypermedia and Telecommunications 2009. Proceedings..., p. 3296-3300. Chesapeake: AACE, 2009.

LOPES, Maria Immacolata V. Pesquisa em comunicação. 6. ed. São Paulo: Loyola, 2002.

PIRES, César Henrique Santos. Concepção dos docentes da UEMA sobre avaliação institucional. Florianópolis: Insular, 2002. 
RECUERO, Raquel. Um estudo do capital social gerado a partir de redes sociais no Orkut e nos Weblogs. In: COMPÓS, GT Tecnologias Informacionais da Comunicação, Anais... Niterói, 2005. Disponível em: <http:/www.intercom.org.br/papers/regionais/ nordeste2009/>. Acesso em: 27/07/2009.

. Redes sociais na internet. Porto Alegre: Sulina, 2009.

ROUCHY, Jean Claude; DESROCHE, Monique Soula. Instituição e Mudança: Processo Psíquico e organização. São Paulo: Casa do Psicólogo, 2005.

SANCHES. Raquel Cristina Ferraroni. Avaliação institucional. Curitiba: IESDE Brasil, 2009.

SORDI, Mara Regina Lemes de; LUDKE, Menga. Da avaliação da aprendizagem à avaliação institucional: aprendizagens necessárias. Revista Avaliação, Campinas; v. 14, n. 2, p. 253-266, jul. 2009. Disponível em: $<$ http://www.scielo.br/scielo.php?pid=S1414$-40772009000200005 \&$ script=sci_arttext $>$. Acesso em: 15/10/2010.

Texto recebido em 04 de fevereiro de 2011.

Texto aprovado em 18 de outubro de 2012. 